\title{
DETERMINATION OF CONDITIONS FOR EVALUATING FRICTION-WEAR PROPERTIES OF COATINGS
}

\author{
Huu Chien NGUYEN, Emil SVOBODA, Jiří PROCHAZKA, Tomáš DRAŽAN, Horníček JAKUB, \\ Dang Long LE
}

UNOB - University of Defence in Brno, Brno, Czech Republic, EU, huuchien.nguyen@unob.cz

https://doi.org/10.37904/metal.2021.4168

\begin{abstract}
This study was conducted to investigate the determination of the conditions for evaluation friction-wear properties of the thin layers and coatings on structural $16 \mathrm{MnCr} 5$ steel. The AlCrVN coatings with the thickness of $2.0 \mu \mathrm{m}$ were generated on the un-nitrided and nitrided materials under the same conditions. The frictionwear properties of the layers and coatings were evaluated by the ball-on-flat method on The Universal Mechanical Tester 3 (UMT-3) with different test forces. The obtained results showed that the friction-wear properties of AICrVN-coated materials changed markedly when the force reaches a certain value. The most suitable conditions for evaluating the properties of thin hard coatings have been determined.
\end{abstract}

Keywords: Plasma nitriding, AICrVN coating, duplex coating, friction-wear properties, ball-on-flat test

\section{INTRODUCTION}

It has been reported that the duplex coatings composed nitrided layers and thin hard coatings improved markedly mechanical, friction-wear properties of steels [1], [2]. The plasma nitriding technology was mostly used primarily to increasing of surface hardness, wear resistance, corrosion resistance and fatigue strength [3], [4], [5], [6], [7], [8]. Nitrided layers formed by plasma nitriding improved adhesion and wear resistance of the thin hard coatings [9]. The AICrVN coating have been investigated in many studies to improve the frictionwear properties of materials [9], [10]. The AICrVN coatings exhibited low friction coefficient of 0.2 and good wear resistance at high temperature $\left(700^{\circ} \mathrm{C}\right)[10]$.

The ball-on-disc and ball-on-flat methods are the most common laboratory methods for evaluating the tribological properties of materials, especially the evaluation of adhesive, abrasive wear [11], [12], [13]. The advantages of the ball-on-flat method over the ball-on-disc method are the simplicity of test specimen preparation and the accurately of wear evaluation. Due to the limited adhesion of the thin hard coatings to the substrate, the coating could be delaminating damaged under high stress during the test. In this case, the results of the experiments do not correctly reflect the friction-wear properties of the coatings. Therefore, it is important to determine appropriate test conditions, in particular the load when evaluating the tribological properties of layers and coatings using the ball-on-flat method.

This study was conducted to determine of the conditions for evaluation friction-wear properties of the thin compound layer and AICrVN coatings. As the substrate, DIN $16 \mathrm{MnCr} 5$ structural steel, which was widely used for higher stressed components production, such as gears, shafts, crankshafts, connecting rods, camshafts, etc., was selected. The AICrVN coatings were coated on both un-nitrided and nitrided substrates under the same conditions. Friction-wear tests were conducted on the UMT-3 tribometer with different test forces for evaluating friction-wear properties of the materials. The profiles of the wear track cross sections were obtained by Talysurf CLI 1000 stylus profilometer using absolute inductive position sensor. 


\section{MATERIALS AND EXPERIMENTAL PROCEDURES}

\subsection{Materials}

Chemical composition of the $16 \mathrm{MnCr} 5$ structural steel used in this study was evaluated by spark emission equipment Q4 TASMAN. The measurement chemical composition of steel was performed five times and the averages are showed in (Table 1).

Table $116 \mathrm{MnCr} 5$ structural steel chemical composition [\%]

\begin{tabular}{|c|c|c|c|c|c|c|c|}
\hline \multicolumn{2}{|c|}{ Elements } & C & Mn & Si & Cr & P & S \\
\hline \multirow{3}{*}{ EN 10084-2008 } & max. & 0.19 & 1.40 & 0.37 & 1.10 & 0.035 & 0.035 \\
\cline { 2 - 8 } & min. & 0.14 & 1.10 & 0,17 & 0,80 & - & - \\
\hline \multicolumn{2}{|c|}{ Measured } & $\begin{array}{c}0.18 \\
\pm 0.01\end{array}$ & $\begin{array}{c}1.10 \\
\pm 0.05\end{array}$ & $\begin{array}{c}0.35 \\
\pm 0.02\end{array}$ & $\begin{array}{c}1.10 \\
\pm 0.01\end{array}$ & $\begin{array}{c}0.023 \\
\pm 0.005\end{array}$ & $\begin{array}{c}0.01 \\
\pm 0.005\end{array}$ \\
\hline
\end{tabular}

The specimens used in the experiment are disc-shaped in diameter of $6.5 \mathrm{~cm}$ and a thickness of $5 \mathrm{~mm}$. The surface of the samples was wet grinded by Struers LaboPol-60 grinder to obtain the same surface roughness $\mathrm{Ra}(0.09 \mu \mathrm{m})$ in order to eliminate the effect of roughness on the friction-wear properties. For grinding, the Silicon Carbide Grinding papers grit 120, 220, 800, 1200 were used. The metallographic test sections of the specimens were polished to mirror surfaces using Leco CAMEO Disc Platium 1, 2, 3, 4 and diamond polishing paste with grain size $1 \mu \mathrm{m}$ by Leco PX-500 Grinder/Polisher.

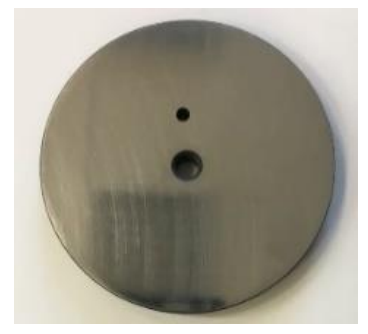

Figure 1 Feature of samples

Four types of materials were prepared for this study. The untreated material, plasma-nitrided material are called UN, PN materials, respectively. The AICrVN coating to untreated material was performed and this AICrVN-coated material is called AICrVN material (AICrVN coating). Hereafter, the AICrVN coating to nitrided material was carried out. This hybrid-surface-treated material is called PN/AICrVN material (AICrVN duplex coating).

Plasma nitriding process was carried out in the PN 60/60 Rübig equipment at a temperature of $470{ }^{\circ} \mathrm{C}$ for $4 \mathrm{~h}$ in a $280 \mathrm{~Pa}$ gas mixture of $\mathrm{H}_{2}$ flow $8 \mathrm{l} / \mathrm{min}$ and $\mathrm{N}_{2}$ flow $24 \mathrm{l} / \mathrm{min}$. The AICrVN coating were performed in the company LISS using cathodic-arc deposition method.

\subsection{Experiment procedures}

The surface roughness parameter Ra was measured by a profilometer Talysurf CLI 1000. Ra is widely used because the surface roughness assessment according to $\mathrm{Ra}$ is relatively inexpensive [14].

After polishing to mirror surfaces, the test cross sections were etched by $2 \%$ Nital etchant (a solution of ethanol and nitric acid). The microstructure of the nitrided layer and the feature of AICrVN coatings were observed on the cross sections of the disc specimens by Olympus DSX500i opto-digital microscope. The thickness of the AICrVN coatings was measured on the cross sections using optical method by Olympus LEXT 3000 laser confocal microscope. The microhardness profile of the nitrided layer was obtained in the range from the surface to depth of $0.5 \mathrm{~mm}$ on the polished cross section of PN material with the load of $0.981 \mathrm{~N}$ by Vickers method on the LECO LM247/AT Microhardness Tester. Based on the results of the microhardness test, the thickness of the nitrided layer was determined according to DIN 50 190-3 [15].

The friction-wear properties of the materials were evaluated using the linearly reciprocating ball-on-flat sliding wear test on Bruker UMT-3 tester. To obtain stable results, Tungsten carbide balls with the hardness of 1800 HV10 were used as the opposite material. The conditions of the test are showed in (Table 2). 
Table 2 Conditions of the friction-wear tests [12]

\begin{tabular}{|c|c|c|c|c|c|c|c|}
\hline Parameter & $\begin{array}{c}\text { Ball diameter } \\
(\mathrm{mm})\end{array}$ & $\begin{array}{c}\text { Stroke length } \\
(\mathrm{mm})\end{array}$ & $\begin{array}{c}\text { Oscillating } \\
\text { frequency }(\mathrm{Hz})\end{array}$ & $\begin{array}{c}\text { Test duration } \\
(\mathrm{s})\end{array}$ & $\begin{array}{c}\text { Ambient } \\
\text { temperature }\left({ }^{\circ} \mathrm{C}\right)\end{array}$ & $\begin{array}{c}\text { Relative } \\
\text { humidity }(\%)\end{array}$ & \begin{tabular}{c} 
Lubrication \\
\hline Value
\end{tabular} \\
6.35 & 10 & 5 & 1000 & $22 \pm 0.5$ & $40-60$ & None \\
\hline
\end{tabular}

The above test parameters were remained stable to eliminate the effect of these parameters on the frictionwear properties of materials for all friction-wear tests. The friction-wear tests were performed with different test forces to select the most suitable force to evaluate the tribological properties of layers and coatings. The test forces of friction-wear test were $5 \mathrm{~N}, 10 \mathrm{~N}, 12 \mathrm{~N}, 20 \mathrm{~N}$ and $25 \mathrm{~N}$.

The cross-sectional profiles of the wear track were evaluated using stylus profilometer Talysurf CLI 1000 with the absolute inductive sensor at eleven locations equally spaced along its length. From the recorded data, the mean cross-sectional profiles were obtained. The track cross-sectional area and track maximal cross-sectional depth (wear depth) were determined using the Talymap Platium software. The total volume of material removed during sliding (the wear volume) was computed from the track cross-section area and the length of stroke [11].

\section{RESULTS}

\subsection{Microstructure and hardness profile}

Figure 2 shows the features of the nitrided layer and the PN/AICrVN duplex coating. Figure 3 shows the microhardness profile of the nitrided layer.

According to the results of the measuring by laser confocal microscope, the thickness of the AICrVN coatings was $2.0 \pm 0.1 \mu \mathrm{m}$. As showed in (Figure 2), a compound layer with thickness $2 \pm 0.5 \mu \mathrm{m}$ was generated on surface of PN material. The thickness of the nitrided layer was $185 \mu \mathrm{m}$, as can be understood from (Figure 3).

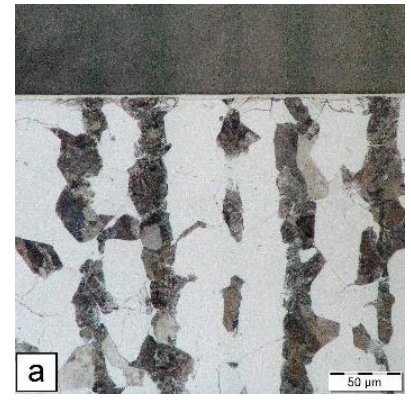

a)

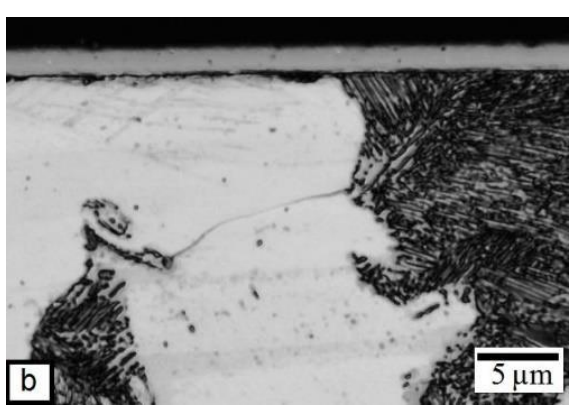

b)

Figure 2 Features of a) nitrided layer, b) PN/AICrVN duplex coating

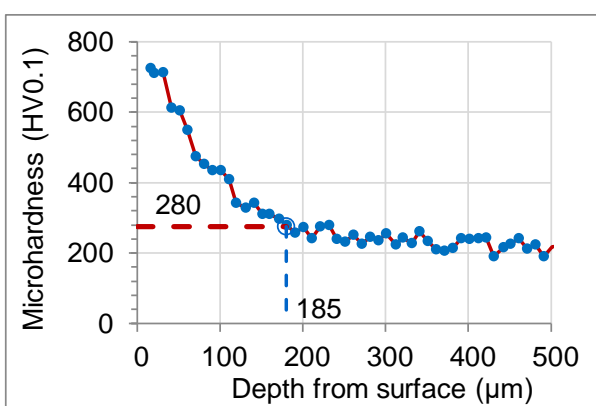

Figure 3 Hardness profile measured on cross section of $\mathrm{PN}$ material

\subsection{Friction-wear properties}

Figure 4 shows the relationship between the test time and the friction coefficients at test force of $5 \mathrm{~N}$. Figure 5 shows the relationship between the test time and the friction coefficients, the features of the wear tracks, the mean cross-sectional profiles of the wear track for other test force. Figure 6 shows the wear volumes and wear depth of materials at different test forces.

At a test force of $5 \mathrm{~N}$, there was no sharp change in the friction coefficients after the running-in period. The friction coefficients of all materials fluctuated slightly. 
With a test force of $5 \mathrm{~N}$, the wear amount of the samples is very small. Therefore, it was so hard to accurately evaluate the wear volume and wear depth of materials, especially for the PN and PN/AICrVN material.

As can be understood from (Figure 5), the relationship between the time test and the friction coefficients at a test force of $10 \mathrm{~N}$ were almost similar that at test force of $5 \mathrm{~N}$ for all materials. The wear volume of the PN/AICrVN material was the lowest (Figure 6a). The wear volume of the PN material was lower than the value of the AICrVN. The wear volume of the UN material was highest. During the test, there were not failures of coatings for all AICrVN-coated materials (Figure 5).

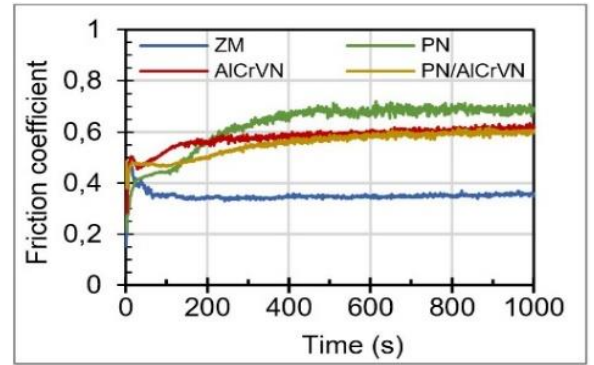

Figure 1 Relationship between test time and friction coefficients at $5 \mathrm{~N}$

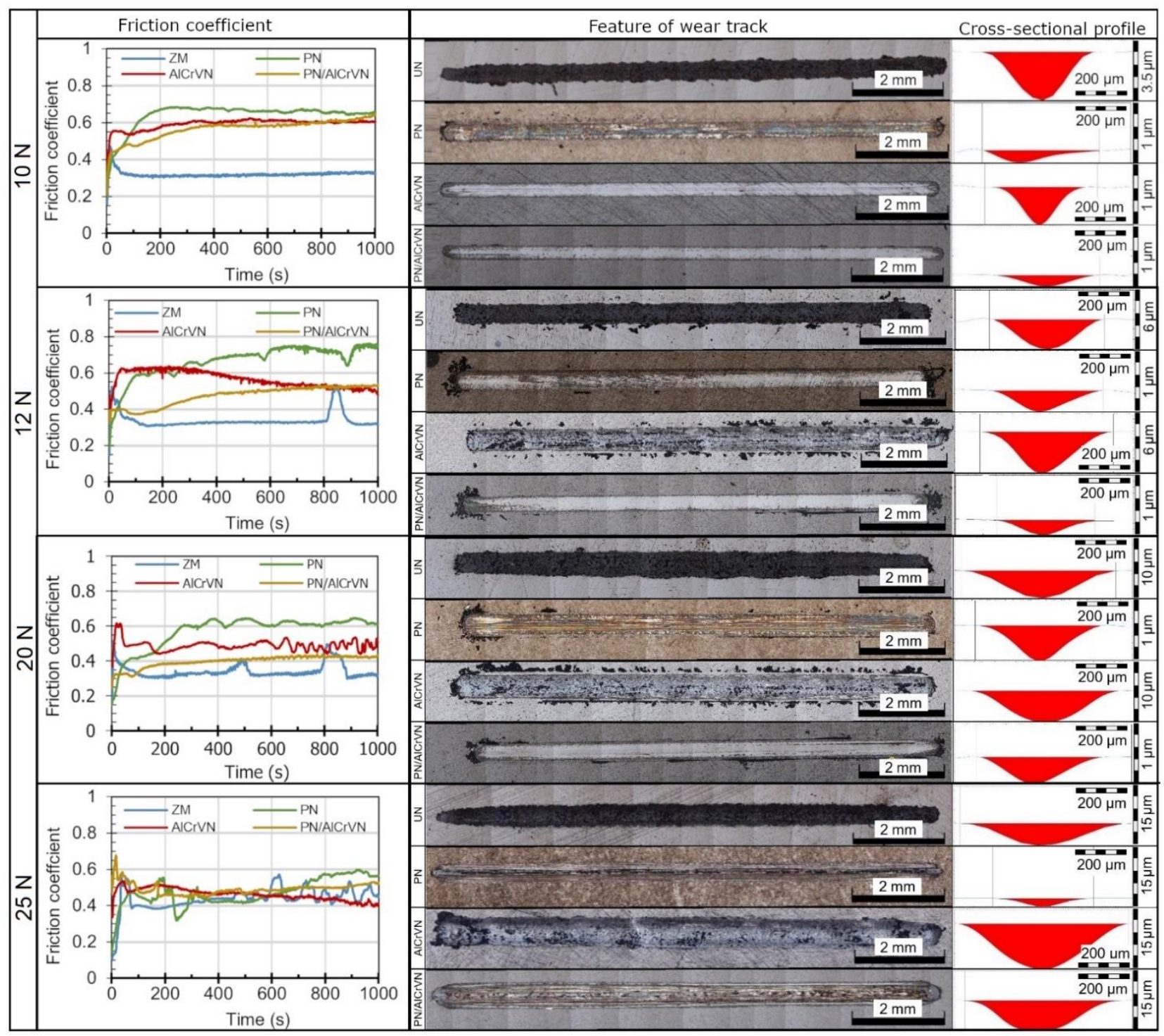

Figure 2 Relationship between time test and friction coefficients; features and mean cross-sectional profiles of wear tracks 
The friction-wear properties of each material at a test forces of $12 \mathrm{~N}$ and $20 \mathrm{~N}$ were similar. At a test force of $12 \mathrm{~N}$, from the test time of $300 \mathrm{~s}$, the friction coefficients of the AICrVN material started decreasing because the AICrVN coating was gradually damaged and wear proceeded to the substrate. At a test force of $20 \mathrm{~N}$, from the test time of $50 \mathrm{~s}$, the friction coefficients of the AICrVN material dropped because the AICrVN coating was markedly damaged. In contrast, there were not failure of the AICrVN coating on PN/AICrVN material. At a test force of $12 \mathrm{~N}$ and $20 \mathrm{~N}$ the wear volume of the AICrVN material was higher than that of the UN material due to the damage of the AICrVN coating. The wear volume of the UN material was markedly higher than the value of PN material. The wear volume of the PN/AICrVN was lowest (Figure 6a).
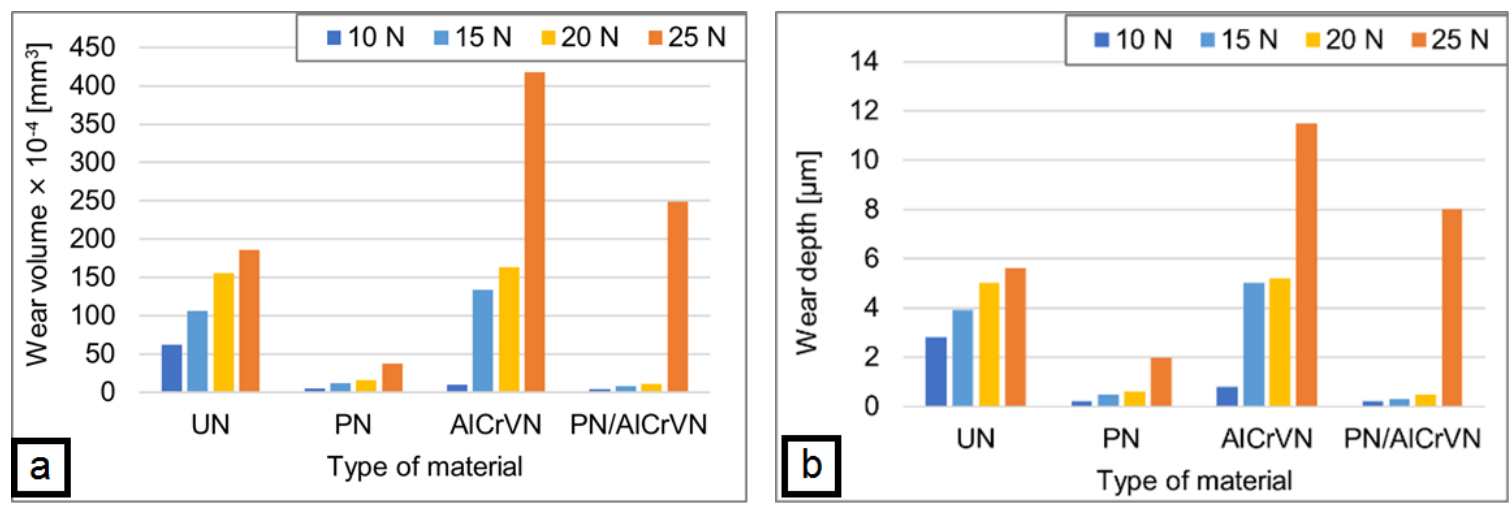

Figure 3 a) Wear volume, b) wear depth at different test forces

At a test force of $25 \mathrm{~N}$, the friction coefficients started dropping from test time of $50 \mathrm{~s}$ for AICrVN material and from $30 \mathrm{~s}$ for PN/AICrVN material due to marked damage of the AICrVN coatings and wear proceeded to the substrate. The friction coefficients of PN material markedly fluctuated in interval (180-330) s because the compound layer was gradually damaged. The wear volumes of the AICrVN-coated materials were higher than the value of the UN material; however, the wear volume of the PN material was lower (Figure 6a).

For the test forces above $10 \mathrm{~N}$, there occur upward peaks in the friction coefficient curve after the running-in period for UN material. These changes of the friction coefficient were caused by the changes of properties wear debris layer formed on the worn substrate [16], [17]. The chemical composition of the wear debris layers can be evaluated using the method energy dispersive X-ray spectroscopy (EDX) on the transmission electron microscope [18].

As can be understood from (Figure 6), with the increasing test force the wear volume and wear depth has increased. The wear volume of AICrVN material increased dramatically with the increasing test force from 10 $\mathrm{N}$ to $12 \mathrm{~N}$ and from $20 \mathrm{~N}$ to $25 \mathrm{~N}$. However, the wear volume of PN/AICrVN material and PN material increased dramatically only with the increasing test force from $20 \mathrm{~N}$ to $25 \mathrm{~N}$. This kind of increasing in wear volume with increasing test force did not occur for UN material.

At test forces above $10 \mathrm{~N}$ for AICrVN material and above $20 \mathrm{~N}$ for PN/AICrVN material, the wear depth was greater than the AICrVN coating thickness. At test forces above $20 \mathrm{~N}$ for PN material, the wear depth was greater than the compound layer thickness. This means that, after the layers had been damaged, the wear proceeded to the substrate for AICrVN-coated materials. After damaged compound layer, the wear proceeded to the diffusion layer for PN material (Figure 5). With damaging of coatings, small pieces of the coating were peeled off and formed hard particles. These particles acted in the frictional process as the abrasive particles between the specimen surfaces. Hence, after damaged coating, the wear speed of the AlCrVN-coated materials increased markedly. The wear volume of AICrVN-coated materials was much greater than the untreated material (Figure 6). In this case, the obtained result cannot be used to evaluate the friction-wear properties of the AICrVN coatings. 
From the obtained results, the test force of $5 \mathrm{~N}$ is unsuitable (too low) to evaluate the friction-wear properties of AICrVN coatings. The test force of $12 \mathrm{~N}, 20 \mathrm{~N}$ and $20 \mathrm{~N}$ were unsuitable (too high) to evaluate the frictionwear properties of the AICrVN coating. However, the test force of $12 \mathrm{~N}$ and $20 \mathrm{~N}$ can be used to evaluate the friction-wear properties of nitrided layer and AICrVN duplex coating. The test force of $25 \mathrm{~N}$ was unsuitable (too high) to evaluate the friction-wear properties of the nitrided layer and AICrVN coatings. To reduce the test time while ensuring the wear is large enough, the most suitable test force is the largest of the forces that can be used. The most suitable test force to evaluated friction-wear properties for AICrVN material and for PN/AICrVN, $\mathrm{PN}$ material was $10 \mathrm{~N}$ and $20 \mathrm{~N}$, respectively.

At a test force of $10 \mathrm{~N}$ after a test duration of $1000 \mathrm{~s}$, the wear volume of the nitrided layer and the duplex coating reached very small values (Figure. 6). Due to the small wear volume, the results of experiments cannot clearly show the influence of selected technologies on the wear properties of the steel. Furthermore, with a small wear depth, it was hard to evaluate accurately wear due to the effect of surface roughness.

Under certain test conditions, the wear volume can be increased by extending the test duration. However, the test duration should be chosen so that the wear does not exceed all of the coating. For the AICrVN material, the wear depth was $0.6 \mu \mathrm{m}$ for test duration $1000 \mathrm{~s}$. Under the same conditions, the additional friction-wear test with a test duration of $2000 \mathrm{~s}$ was performed, in which an increase in the wear depth by $1.2 \mu \mathrm{m}$ to approximately $2 \mu \mathrm{m}$ can be expected. Figure 7 shows the features of the wear tracks and the mean profiles of the wear track cross sections for test force of $10 \mathrm{~N}$, test duration of $2000 \mathrm{~s}$.

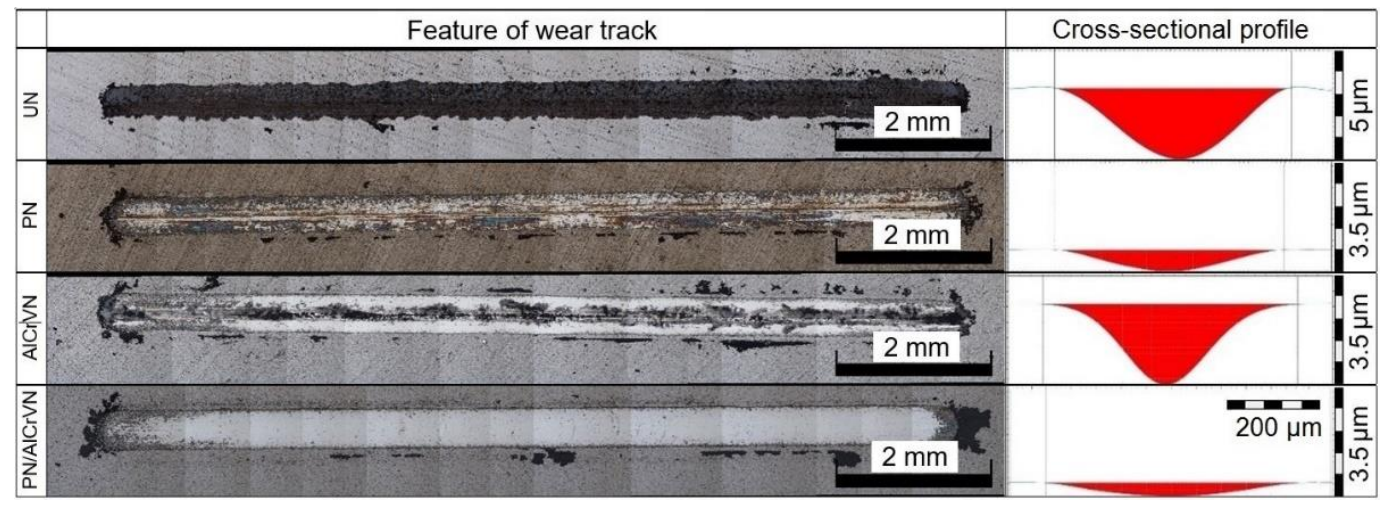

Figure 7 Features and mean cross-sectional profiles of wear tracks at test force of $10 \mathrm{~N}$, test duration of $2000 \mathrm{~s}$

Table 3 Wear volume and wear depth at test duration of 1000 s, $2000 \mathrm{~s}$ (test force of $10 \mathrm{~N}$ )

\begin{tabular}{|c|c|c|c|c|c|c|c|c|}
\hline Test duration $(\mathbf{s})$ & \multicolumn{4}{|c|}{1000} & \multicolumn{4}{c|}{2000} \\
\hline Material & UN & PN & AICrVN & PN/AICrVN & UN & PN & AICrVN & PN/AICrVN \\
\hline Wear volume $\times 10^{-4}\left(\mathrm{~mm}^{3}\right)$ & 62 & 5 & 10 & 4 & 90 & 19 & 47 & 14 \\
\hline Wear depth $(\mu \mathrm{m})$ & 2.8 & 0.2 & 0.6 & 0.2 & 3.5 & 0.7 & 2.6 & 0.6 \\
\hline
\end{tabular}

As can be understood from (Table 3), the wear depth of AICrVN material was higher than the coating thickness. However, the coating AICrVN only was worn through in the small area of wear track (Figure 7). The wear volume of nitrided and AICrVN-coated materials increased from 3.5 to 4.5 times. The wear depth of PN material and AICrVN-coated materials increased from three to four times. The test duration of $2000 \mathrm{~s}$ was more suitable than that of $1000 \mathrm{~s}$ to evaluate wear properties of nitrided layer and AICrVN coatings.

The obtained results suggested that, the test force of $10 \mathrm{~N}$ and the test duration of 2000s was most suitable to evaluate the friction-wear properties for all coatings and layers on $16 \mathrm{MnCr} 5$ steel using the ball-on-flat method. 


\section{CONCLUSION}

The suitable conditions of the ball-on-flat test were determined to evaluate friction-wear properties of nitrided layer and AlCrVN coatings on $16 \mathrm{MnCr} 5$ steel.

The choice of test force has a great influence on the results of the evaluation of the friction-wear properties of the layers and coatings by method ball-on-flat. The test force of $5 \mathrm{~N}$, at which the wear of treated materials was too low, was unsuitable to evaluate wear resistance. The test force of $25 \mathrm{~N}$, at which all layers were damaged were too high for friction-wear test. There were not failures of AICrVN duplex coating at test force of $12 \mathrm{~N}, 20 \mathrm{~N}$. However, the AICrVN coating on un-treated material was gradually damaged at these test forces. The test force of $10 \mathrm{~N}$, at which damaging did not occur for all coatings was the most suitable force to evaluate friction-wear properties of coatings.

The wear volume increased dramatically with increasing test force to the value, at which the layers, coatings were damaged. To reduce the test time while ensuring the wear is large enough, the most suitable test force is the greatest force, which does not damage the coatings and layers.

\section{ACKNOWLEDGEMENTS}

The work presented in this paper has been supported by the specific research project 2020 "SV20216"at the Department of Mechanical Engineering, University of Defence in Brno and the Project for the Development of the Organization "DZRO Military autonomous and robotic systems".

\section{REFERENCES}

[1] JOSKA, Z., KADLEC, J., HRUBÝ, V., et al. Mechanical properties of duplex treated AISI 316L stainless steel. In: METAL 2011: 20th Anniversary International Conference on Metallurgy and Materials. Ostrava: TANGER, 2011, pp. 724-728.

[2] JOSKA, Z., KADLEC, J., HRUBY, V., et al. Investigation of diamond like carbon coating deposited on plasma nitrided austenitic stainless steel. Chemické listy. 2012, vol. 106, issue SI, pp. S446-S447.

[3] KADLEC, J., JOSKA, Z., POKORNÝ, Z. Plasma Treatment of Stainless Steel Surface. ECS Transactions. 2010, vol. 32, Issue 1, pp. 69-72.

[4] POKORNÝ, Z., HRUBÝ, V. Plasma nitriding of deep narrow cavities. Key Engineering Materials. 2010, vol. 465, pp. 267-270.

[5] DOBROCKÝ, D., STUDENÝ, Z., POKORNÝ, Z. Effect of plasma nitriding on the notch toughness of spring steel. In: METAL 2016: 25th Anniversary International Conference on Metallurgy and Materials. Ostrava: TANGER, 2016, pp 1037-1045.

[6] STUDENÝ, Z., KUŠMIC, D. Influence of inclusions size on the nitrided components fatigue life. In: METAL 2014: 23th Anniversary International Conference on Metallurgy and Materials. Ostrava: TANGER, 2014, pp. 875-880.

[7] POKORNÝ, Z., DOBROCKÝ, D., KADLEC, J., STUDENÝ, Z. Influence of alloying elements on gas nitriding process of high-stressed machine parts of weapons. Kovové materially - Metallic materials. 2018, vol. 56, issue 2, pp. 97-103.

[8] PROCHÁZKA, J., POKORNÝ, Z., DOBROCKÝ, D. Service behaviour of nitrided layers of steels for military applications. Coatings. 2020, vol. 10, issue 10, Article number 975.

[9] SINDRA, I., FEI CAI, J.W., et al. Effect of addition of Mo or V on the structure and cutting performance of AICrNbased coatings. Coatings. [online]. 2020, vol. 10, no. 3, pp. 1-11. Available from:

https://doi.org/10.3390/coatings10030298.

[10] ROBERT, F., BERNHARD, S., et al. High-temperature, low-friction properties of the Vanadium alloyed AICrN coatings. Tribology letters. [online]. 2006, vol. 23, no. 2. Available from:

https://doi.org/10.1007/s11249-006-9064-1.

[11] ASTM G155-04. Standard Guide for Measuring and Reporting Friction Coefficients. West Conshohocken, PA, USA: ASTM International, 2004. 
[12] ASTM G133-02. Standard Test Method for Linearly Reciprocating Ball-on-Flat Sliding Wear. West Conshohocken, PA, USA: ASTM International, 2002.

[13] ASTM G99-95. Standard Test Method for Wear Testing with a Pin-on-Disk Apparatus. West Conshohocken, PA, USA: ASTM International, 1995.

[14] BARÉNYI, I., MAJERÍK, J., POKORNÝ, Z., SEDLÁK, J., BEZECNÝ, J., DOBROCKÝ, D., JAROŠ, D., ECKERT, M., JAMBOR, J., KUSENDA, D. Material and technological investigation of machined surfaces of the OCHN3MFA steel. Kovové materially - Metallic materials. 2019, vol. 57, issue 2, pp. 131-142.

[15] DIN 50190-3:1979. Hardness depth of heat-treated parts; determination of the effective depth of hardening after nitriding. German: German Institute for Standardisation, 1979.

[16] ALFERED, Z. Wear debris: a review of properties and constitutive models. J. Theor. Appl. Mech. 2005, vol. 43, no. 1, pp. 3-35.

[17] HONGXIN, S., SANMING, D., CHAO, S., CHENFEI, S., ZHENGHAI, Y., YONGZHEN, Z. Behaviour of wear debris and its action mechanism on the tribological properties of medium-carbon steel with magnetic field. Materials (Basel). [online]. 2018, vol. 12, no. 1, pp. 14-16. Available from: https://doi.org/10.3390/ma12010045.

[18] ROBL, J., SEDLÁK, J., POKORNÝ, Z., ŇUKSA, P., BARÉNYI, I., and MAJERÍK, J. Analysis of advanced additive technology in direct metal laser sintering and precision casting method. BULLETIN OF THE POLISH ACADEMY OF SCIENCES TECHNICAL SCIENCES. [online]. 2020, vol. 68, no. 1, pp. 109-118. Available from: https://doi.org/10.24425/bpasts.2020.131842. 